\title{
Genetic Relationship with Confluence of the Plants
}

\author{
Mahdi Tajalifar* \\ University of Genetics and Plant Breeding, Iran \\ *Corresponding Author: Mahdi Tajalifar, University of Genetics and Plant Breeding, Iran.
}

Received: October 31, 2019; Published: November 08, 2019

DOI: 10.31080/ASAG.2019.03.0716

\begin{abstract}
In multicellular organism but, meiosis is limited to the germplasm, where it is template for sexual reproductive.

Take notice of somatic cells process mitosis to increase, the germplasm process meiosis to create haploid gametes (the sperm and the egg). The extension of a new offspring organisms next started by the cross of these cells at zygosis.
\end{abstract}

Keywords: Multicellular; Meiosis; Germplasm; Haploid; Offspring

\section{Introduction}

But into mitosis, meiosis resultant are in division of a diploid parental cell into haploid offspring. Both meiosis and mitosis start next DNA duplicate, so every complex of two sister chromatids. At complete of meiosis every daughter cell has then adventitious one organ of every homologous match, containing of two sister chromatids. The genetic modified of plant drought resistore by choice for crop under strain is a feasible but a prolonged and knotty program. The empirical phylogenetic literature on plant variegation, denoting challenges in isolation the tracks of speciation and overthrow, in state variegation mechanisms, and in production cogent earmark.

\section{Division meiosis}

Against to mitosis, meiosis affects in dealing of a diploid parent cell into haploid offspring, every including only one organ of the match of homologous chromosomes that were present in the diploid parent. The quality and mechanism of the meiotic cell repartition in plants and its effect on genetic variability are surveyed here. As flowers are the site of meiosis and cross pollinate in angiosperms, meiotic control will be considered within this spread basis.

\section{Genetic in relation to plant breeding}

Chief genetic and physiological data to be used or further modified of the choice systems. Plant breeding is an program of genetic principles to the improvement of plants. The following genetic tenet are useful to modify the inheritance of plants.

\section{Confluence of the plants}

These ideas by considering how rate heterogeneity united with a connection relates to the being of particularly species poor lineage, or depauperons. In a way, ordinary plant breeding can be seen as a collection of techniques targeted at affording together good parents to production a better crop in offspring. A class of sequenced marriage. It is then essential for plant breeders to all sure of whom the parents of a cross [1-6].

\section{Conclusion}

Against to meiosis, meiosis result in dealing of a diploid parent cell into haploid offspring. Chief genetic and physiological data to be used or further modified of the choice systems.

In a way, ordinary plant breeding can be seen as a collection of techniques targeted at affording together good parents to production a better crop in offspring. 


\section{Bibliography}

1. www.ncbi.nlm.nih.gov/books/Npk9901/

2. academic.oup.com/jxb/article/61/11/2863/440786

3. www.sciencedirect.com/science/article/ pli/0378377483900835

4. www.agriinfo.in/default.aspx

5. www.ncbi.nlm.nih.gov/pubmed/25788694

6. blfa.org/bioscience-n-brif/plantbreeding/plantbreederscrossplant/

Volume 3 Issue 12 December 2019

(C) All rights are reserved by Mahdi Tajalifar. 